\title{
1 Unravelling the active microbial community in a thermophilic anaerobic 2 digester-microbial electrolysis cell coupled system under different conditions
}

$4 \quad$ Míriam Cerrillo ${ }^{1}$, Marc Viñas ${ }^{1}$, August Bonmati $1^{1 *}$.

$5{ }^{1}$ IRTA. GIRO Joint Research Unit IRTA-UPC. Torre Marimon. E-08140, Caldes de Montbui, Barcelona 6 (Spain).

7 * Corresponding author. E-mail address: august.bonmati@irta.cat (A. Bonmatí)

\section{ABSTRACT}

Thermophilic anaerobic digestion (AD) of pig slurry coupled to a microbial electrolysis cell (MEC) with a recirculation loop was studied at lab-scale as a strategy to increase AD stability when submitted to organic and nitrogen overloads. The system performance was studied, with the recirculation loop both connected and disconnected, in terms of $\mathrm{AD}$ methane production, chemical oxygen demand removal (COD) and volatile fatty acid (VFA) concentrations. Furthermore, the microbial population was quantitatively and qualitatively assessed through DNA and RNA-based qPCR and high throughput sequencing (MiSeq), respectively to identify the RNA-based active microbial populations from the total DNA-based microbial community composition both in the AD and MEC reactors under different operational conditions. Suppression of the recirculation loop reduced the $\mathrm{AD}$ COD removal efficiency (from $40 \%$ to $22 \%$ ) and the methane production (from 0.32 to $0.03 \mathrm{~m}^{3} \mathrm{~m}^{-3} \mathrm{~d}^{-1}$ ). Restoring the recirculation loop led to a methane production of $0.55 \mathrm{~m}^{3} \mathrm{~m}^{-3} \mathrm{~d}^{-1}$ concomitant with maximum MEC COD and ammonium removal efficiencies of $29 \%$ and $34 \%$, respectively. Regarding microbial analysis, the composition of the $\mathrm{AD}$ and $\mathrm{MEC}$ anode populations differed from really active microorganisms. Desulfuromonadaceae was revealed as the most active family in the MEC (18\%$19 \%$ of the RNA relative abundance), while hydrogenotrophic methanogens (Methanobacteriaceae) dominated the AD biomass.

\section{Keywords} expression, cDNA sequencing 
Anaerobic digestion (AD) is a technology that has been widely used since the beginning of the twentieth century to treat animal, municipal and industrial wastes, producing biogas, a form of renewable energy (Yenigün et al. 2013) as a by-product. One of its weak points is the sensitivity of methanogens, one of the main groups involved in the process, to chemical and environmental stressors, especially under thermophilic conditions (Chen et al. 2008). Certain inhibitory substances or process conditions may lead to the anaerobic reactor upset and failure indicated by a decrease in methane gas production and the accumulation of volatile fatty acids (VFA). Different strategies for recovering inhibited reactors have been evaluated, such as reactor feeding patterns, dilution and addition of absorbents for fast recovery after the inhibition of an AD reactor due to the presence of long chain fatty acids (LCFA) (Palatsi et al. 2009); electrochemical nutrient recovery (Desloover et al. 2014; Sotres et al. 2015a) or the use of membrane contactors (Lauterböck et al. 2012) for ammonia toxicity control; $\mathrm{pH}$ reduction or the addition of zeolite, biomass or humic acid have also been strategies used to recover ammonia-inhibited thermophilic processes (Ho et al. 2012). Ammonia inhibition is one of the main issues to deal with when treating high strength wastes such as livestock manure, hence being the topic in a wide range of studies and reviews (Yenigün et al. 2013).

Combining AD and bioelectrochemical systems (BES) such as microbial electrolysis cells (MEC) has been previously reported as a new processing strategy aiming to recover energy and nitrogen (Cerrillo et al. 2016b). On the one hand, this system can help to produce additional energy and to polish the AD effluent, especially when malfunction of the $\mathrm{AD}$ reactor occurs due to an organic overload, attaining a more stable and robust system. And on the other hand, ammonium can be removed and recovered, taking advantage of this process to reduce ammonia inhibition in the AD (Cerrillo et al. 2016b). In a previous study, the microbial community assessment revealed that changes in biomass composition were appreciated with a certain delay with respect to the AD observed performance, in terms of VFA accumulation or methane production (Cerrillo et al. 2016b). This fact points out that an RNA-based approach in AD-BES systems could help us to gain insight on the resilient active microbial key players during an inhibition process. A previous work also demonstrated that the ammonia inhibition of methanogenesis in AD was largely due to the repression of functional gene transcription, rather than to a decrease in total population of methanogenic archaea (Zhang et al. 2014). In fact, DNA only provides information about the existence of bacteria in the 
reactors, but it cannot provide information about their activity and gene expression, which is important to understand which groups are being enhanced by certain environmental or operational conditions. Transcription analysis enables exclusive detection of short-lived messenger RNA (mRNA) produced by active organisms without the potential bias of DNA detection from dormant or dead cells (Munk et al. 2012). In addition, total rRNA, is dependent of ribosome abundance in a bacterial cell, and can be significantly shifted (10-100 folds) from dormant cells in comparison with growing cells (Neidhardt 1996). For this reason, direct extraction of total bacterial RNA (basically mRNA and rRNA) from samples is a key procedure for the subsequent application of qPCR or high throughput sequencing techniques.

The main aim of this study is (1) to assess the combination of the AD process with a microbial electrolysis cell and a recirculation loop as a system to recover $\mathrm{AD}$ reactors that have experienced a process failure, and (2) to study the microbial population in the AD-MEC system during the inhibited and recovered state of the $\mathrm{AD}$ process, with respect to the predominant presence of eubacteria and archaea in the biomass, and also with regards to metabolically active populations, by means of DNA and RNA-based methods.

\section{Materials and methods}

\subsection{Experimental set-up}

An anaerobic thermophilic $4 \mathrm{~L}$ lab-scale continuous stirred tank reactor (AD) was used to study its performance when treating pig slurry. The AD reactor was connected in series to the anode compartment of a two-chambered MEC for ammonia recovery and had a recirculation loop set up between both reactors, as previously described (Cerrillo et al. 2016b). An Ag/AgCl reference electrode (Bioanalytical Systems, Inc., USA) was inserted in the anode compartment of the MEC (+197 mV vs. SHE, all potential values in this paper are referred to SHE) and a potentiostat (VSP, Bio-Logic, Grenoble, France) was used to poise the anode (working electrode) potential at $0 \mathrm{mV}$ in a three-electrode configuration. The potentiostat was connected to a personal computer recording electrode potentials and current every 5-min using EC-Lab software (Bio-Logic, Grenoble, France). The solutions of both the anode and the cathode compartment were fed in continuous mode with a peristaltic pump at $21 \mathrm{~mL} \mathrm{~h}^{-1}$ and mixed by recirculation with an external 
pump. The MEC was operated at room temperature during the entire assay $\left(23 \pm 2{ }^{\circ} \mathrm{C}\right)$. An overview of the complete AD-MEC integrated system can be seen in Cerrillo et al. (2016).

\subsection{Reactors operation}

The raw pig slurry used as AD feed was collected from a farm in Vila-Sana (Lleida, Spain) (Table 1). The hydraulic retention time (HRT) was fixed at 10 days. The reactor was operated during 118 days in 2 different phases, with organic (OLR) and nitrogen (NLR) loading rates of $6.10 \pm 1.88 \mathrm{~kg}_{\mathrm{COD}} \mathrm{m}^{-3}$ day $^{-1}$ and $0.35 \pm 0.04$ $\mathrm{kg}_{\mathrm{N}} \mathrm{m}^{-3}$ day ${ }^{-1}$, respectively (Table 2 ). The AD had been previously operated for 37 days with a recirculation loop set up between the AD and the MEC, to reduce ammonia inhibition phenomena (Cerrillo et al. 2016b). At the beginning of this study, corresponding to Phase 1, the recirculation loop was suppressed, and later enabled again in Phase 2 (50\% of the AD feed flow rate), with the aim to evaluate the effectiveness of this processing strategy to recover $\mathrm{AD}$ after a failure event and to study the changes in biomass. For each experimental condition, specific methane yields $\left(\mathrm{m}^{3}{ }_{\mathrm{CH} 4} \mathrm{~d}^{-1}\right)$, specific methane production rates $\left(\mathrm{m}_{\mathrm{CH} 4}^{3} \mathrm{~m}^{-3} \mathrm{~d}^{-1}\right)$ and COD removal efficiencies were used as control parameters. As well as biogas composition, alkalinity, $\mathrm{NH}_{4}{ }^{+}-\mathrm{N}$ and VFA concentrations in the effluent.

As for the MEC, the digested pig slurry obtained from the AD was used as feed for the anode compartment previously filtering it through a $125 \mu \mathrm{m}$ stainless steel sieve. The catholyte solution for the cathode chamber contained (in deionised water) $\mathrm{NaCl} 0.1 \mathrm{~g} \mathrm{~L}^{-1}$. Samples were periodically taken to analyse $\mathrm{pH}$ and $\mathrm{NH}_{4}{ }^{+}$-N concentration in the anode and cathode effluents, besides COD and VFA concentration in the anode effluent.

\subsection{Analytical methods and calculations}

Chemical oxygen demand (COD), Kjeldahl nitrogen (TKN), ammonium $\left(\mathrm{NH}_{4}{ }^{+}-\mathrm{N}\right), \mathrm{pH}$, total solids (TS), volatile solids (VS), volatile fatty acids (VFAs), biogas composition $\left(\mathrm{N}_{2}, \mathrm{CH}_{4}, \mathrm{CO}_{2}\right)$, partial, total and intermediate alkalinity (PA, TA and IA, respectively), free ammonia nitrogen (FAN), COD and ammonium removal efficiency and the current density $\left(\mathrm{A} \mathrm{m}^{-2}\right)$ obtained in the $\mathrm{MEC}$, were determined and calculated as described elsewhere (Cerrillo et al. 2016b).

PA alkalinity, which roughly corresponds to bicarbonate alkalinity, was obtained by titration, from the original $\mathrm{pH}$ sample, to $\mathrm{pH} 5.75$. TA determination (titration to $\mathrm{pH} 4.3$ ) allowed for IA calculation (titration from 5.75 to 4.3 , roughly corresponding to VFA alkalinity) (Ripley et al., 1986). IA:TA ratio was used as a tool to monitor anaerobic digestion, considering that the process was stable when IA:TA was below 0.3 . 
111 The Coulombic efficiency (CE), or the fraction of electrons resulting from the consumption of COD

112 effectively transformed into current density (Equation 1), was calculated as

$$
\mathrm{CE}=\frac{\mathrm{M} \int_{0}^{\mathrm{t}} \mathrm{Idt}}{\mathrm{F} \mathrm{b} \mathrm{q} \Delta \mathrm{COD}}
$$

113

114

where $M$ is the molecular weight of the final electron acceptor, $I$ is the current (A), $F$ is Faraday's constant, $b$ is the number of electrons transferred per mole of $\mathrm{O}_{2}, q$ is the volumetric influent flow rate $\left(\mathrm{L} \mathrm{s}^{-1}\right)$, and $\triangle C O D$ is the difference between the influent and effluent $\operatorname{COD}\left(\mathrm{g} \mathrm{L}^{-1}\right)$.

\subsection{Microbial community analysis}

Eubacterial and archaeal communities in the $\mathrm{AD}$ at the end of both Phase 1 and 2, and also those communities attached to the anode of the MEC at the beginning and at the end of the experiments, were analysed by culture-independent molecular techniques such as quantitative PCR (qPCR and RT-qPCR) and high throughput DNA and cDNA sequencing of eubacteria and archaea $16 S$ rRNA gene libraries (MiSeq, Illumina). To stabilise the nucleic acid samples they were immediately frozen and stored at $-80{ }^{\circ} \mathrm{C}$ before DNA/RNA extraction.

\subsubsection{Nucleic acid extraction and complementary DNA (cDNA) synthesis}

Total DNA and RNA were extracted in triplicate from known weights of each sample with the PowerMicrobiome $^{\mathrm{TM}}$ RNA Isolation Kit (MoBio Laboratories Inc., Carlsbad, CA, USA), following the manufacturer's instructions. Purified total RNA was obtained by co-extracted DNA removal with DNase I (included in the kit) at $25^{\circ} \mathrm{C}$ for $10 \mathrm{~min}$, and DNase I inactivation with EDTA $50 \mathrm{mM}$ (Thermo Scientific Fermentas, USA) at $75{ }^{\circ} \mathrm{C}$ for $5 \mathrm{~min}$. The reverse transcription PCR (RT-PCR) -for cDNA synthesis- from the RNA obtained was performed using PrimeScript ${ }^{\mathrm{TM}}$ RT Reagent Kit (Takara Bio Inc., Japan). The reaction was carried out in $30 \mu \mathrm{L}$ containing $15 \mu \mathrm{L}$ of purified RNA, $6 \mu \mathrm{L}$ of PrimeScript ${ }^{\mathrm{TM}}$ buffer, $1.5 \mu \mathrm{L}$ of the enzyme mix, $1.5 \mu \mathrm{L}$ of Random 6 mers and $6 \mu \mathrm{L}$ of RNase Free $\mathrm{dH}_{2} \mathrm{O}$. Henceforth, the term cDNA is used to refer to the RNA-based samples.

\subsubsection{Quantitative PCR assay (qPCR)}

Gene copy numbers of eubacterial $16 S$ rRNA gene and mcrA gene (methanogenic archaeal methyl coenzyme-M reductase) from DNA and cDNA were quantified by means of quantitative real-time PCR (qPCR). Each sample was analysed in triplicate using three independent DNA and cDNA (from rRNA and 
mRNA) extracts. This analysis was carried out following the protocol described elsewhere (Cerrillo et al. 2016b).

\subsubsection{High throughput DNA sequencing and data analysis}

The same DNA and RNA extracts, from the anode of the MEC and the AD effluents, used for qPCR analysis were used for high throughput sequencing purposes. The specific steps of MiSeq analysis for eubacteria and archaea were performed as described elsewhere (Cerrillo et al. 2016b). The obtained Operational Taxonomic Units (OTUs) were taxonomically assigned using the Bayesian Classifier tool of the Ribosomal Database Project (RDP) (Wang et al. 2007).

The data obtained from sequencing datasets was submitted to the Sequence Read Archive of the National Center for Biotechnology Information (NCBI), under study accession number SRP071288 for eubacterial and archaeal populations.

Sample diversity was evaluated calculating the number of OTUs, the inverted Simpson index, Shannon index and Goods coverage using Mothur software v.1.34.4 (http://www.mothur.org) (Schloss et al. 2009), normalising all estimators to the lower number of reads among the different samples. The statistical correspondence analysis of MiSeq data was performed by means XLSTAT 2014 software (Addinsoft, Paris, France).

\section{Results and discussion}

\subsection{Inhibition of the AD with the suppression of the recirculation loop (Phase 1)}

The recirculation loop set between the AD and the MEC, in a previous assay (Cerrillo et al. 2016b) operating for 37 days, was suppressed at the beginning of Phase 1. This change in configuration resulted in a failure of the $\mathrm{AD}$, with a $40 \%$ to $22 \%$ drop in COD removal efficiency in two weeks (Figure 1a), an increase in COD effluent, from 41 to $47 \mathrm{~g} \mathrm{~L}^{-1}$, and in methane production, from 0.32 to $0.03 \mathrm{~m}^{3} \mathrm{~m}^{-3} \mathrm{~d}^{-1}$ (Figure $1 \mathrm{~b}$ ). VFA concentration increased up to $10,140 \mathrm{mg}_{\mathrm{COD}} \mathrm{L}^{-1}$, especially propionic $\left(1,215 \mathrm{mg} \mathrm{L}^{-1}\right)$, iso and $\mathrm{n}$-butyric (900 and $561 \mathrm{mg} \mathrm{L}^{-1}$, respectively), and iso and n-valeric (561 and $918 \mathrm{mg} \mathrm{L}^{-1}$, respectively) (Figure 1c), in parallel with a IA:TA ratio increase to 0.49 (Figure 1c). The IA:TA ratio is a parameter used as an indicator of AD stability and values higher than 0.30 are considered as a sign of reactor inhibition. On the other hand, 
it has been reported that propionic acid concentrations of $900 \mathrm{mg} \mathrm{L}^{-1}$ result in a significant methanogen inhibition (Wang et al. 2009). The concentration of propionic acid in the AD was above this value. Hence, the observed inhibition was probably due to VFA rather than ammonia concentration, since the highest free ammonia nitrogen (FAN) was of $732 \mathrm{mg} \mathrm{L}^{-1}$ (data not shown), far from the inhibition value of $900 \mathrm{mg} \mathrm{L}^{-1}$ (Angelidaki et al. 1993). However, FAN levels may have inhibited certain groups of methanogens, such as acetotrophs, which show lower tolerance towards FAN than hydrogenotrophs (Angelidaki et al. 1993; Lee et al. 2014).

$\mathrm{AD}$ behaviour during this phase indicates that the recirculation loop improved the system in terms of stability and robustness, whereas its suppression resulted in the inhibition of the biomass. As described in Cerrillo et al. (2016), the beneficial effect of the recirculation loop set between the MEC and the AD can be due to i) ammonia inhibition decrease in the $\mathrm{AD}$, by ammonium removal and the slight decrease in $\mathrm{pH}$ of the digestate in the MEC; ii) reduction of the organic load of the $\mathrm{AD}$, thanks to the MEC removing part of the remaining COD and VFAs; and iii) biomass interaction between both reactors.

\subsection{Recovery of the AD after restarting the recirculation loop (Phase 2)}

When the recirculation loop set between the $\mathrm{AD}$ and the $\mathrm{MEC}$ was connected again, the $\mathrm{AD}$ showed a fast recovery in methane production, with values up to $0.55 \mathrm{~m}^{3} \mathrm{~m}^{-3} \mathrm{~d}^{-1}$, a 1.7 -fold increase with respect to the initial values in Phase 1 (Figure 1b). COD removal efficiency continued to decrease for 3 weeks after connecting the recirculation loop, with a subsequent progressive increase to values of $46 \%$ (effluent COD of $32 \mathrm{~g} \mathrm{~L}^{-1}$ ), slightly higher than the initial ones in Phase 1 (Figure 1a). Acetic acid concentrations showed an increase during the same 3-week period of lower COD removal efficiency, achieving values of $6,000 \mathrm{mg} \mathrm{L}^{-1}$. All VFA values also later decreased to initial figures (Figure 1c). The same behaviour was observed with respect to the IA:TA ratio (Figure 1d), achieving values close to 0.30 at the end of this Phase, thus improving the initial one. The recovery in methane production with IA:TA ratio values above 0.30 suggests that the AD may be operating under an 'inhibited steady state' as previously suggested by Angelidaki and Ahring (1993). The MEC achieved a maximum COD and ammonium removal efficiency of $29 \%$ and $34 \%$, respectively, concomitant with average current densities of around $2.5 \mathrm{~A} \mathrm{~m}^{-2}$ (Figure 2). This MEC high performance period is concurrent with the lowest performance period in terms of COD removal efficiency in the AD. The progressive decrease in the current density -and thus in ammonium removal- shown in the MEC from day 
80 onwards until the end of the assay, is due to the increase in COD removal efficiency in the AD where less organic matter is available to be converted into current in the MEC. In this way, the AD and MEC integrated system allowed to maintain the quality of the effluent regardless of the inhibition of the AD, keeping overall COD removal efficiencies above $35 \%$ during the poorest performance period of the AD, with a maximum of $60 \pm 1 \%$ at the end of the assay (effluent COD of $25 \pm 1 \mathrm{~g} \mathrm{~L}^{-1}$ ). This complementation between the performance of both reactors has also been described in a previous work (Cerrillo et al. 2016b), and it not only allows to stabilise the $\mathrm{AD}$, but also to polish the obtained effluent during $\mathrm{AD}$ malfunction periods.

The Coulombic efficiency (CE) of the MEC was quite low $(8 \pm 3 \%)$, although still in the range of values obtained in previous works (Cerrillo et al. 2016a). This result can be explained by several factors. On the one hand, the complexity of the substrate used as feed and the probable presence of other electron acceptors. On the other hand, the anode compartment of the MEC was operated with high OLRs $\left(35 \mathrm{~kg}_{\mathrm{COD}} \mathrm{m}^{-3} \mathrm{day}^{-1}\right)$, a fact that can result in low CEs due to fermentation processes (Sleutels et al., 2016). In that sense, high anode overpotentials can help exoelectrogenic microorganisms to outcompete methanogenic archaea.

The present work has shown that the maintenance of the recirculation loop is necessary to sustain the operation of the $\mathrm{AD}$ under organic and nitrogen overload, suggesting that the improvement of its performance is not due to biomass acclimation.

\subsection{Microbial community assessment}

The microbial community structure and activity of the samples taken from the AD effluent at the end of Phase 1 and 2, and from the carbon felt of the MEC reactor at the beginning and at the end of the assays was characterised by means of total and active eubacteria and methanogenic archaea enumeration, by means of qPCR/RT-qPCR, and DNA and cDNA amplicon sequencing by means of MiSeq.

\subsubsection{Quantitative analysis by qPCR}

Standard curve parameters of the qPCRs performed prove that the reactions were highly efficient and as follows (for $16 S$ rRNA and $m c r A$, respectively): slope of -3.515 and -3.558 ; correlation coefficient of 0.999 and 0.996; efficiency of $93 \%$ and $91 \%$. Figure 3 shows qPCR results of the four samples regarding DNA (existence) and cDNA (active populations), for $16 \mathrm{~S}$ rRNA (eubacteria) and mcrA (methanogenic archaea) gene copy numbers. An increase in gene copy numbers regarding total eubacteria in the AD can be observed 
at the end of Phase 2, when the $\mathrm{AD}$ reactor was recovered after restarting the recirculation loop, with respect to Phase 1 -or inhibited state- either in terms of DNA and cDNA for $16 S$ rRNA and mcrA genes. While $16 S$ rRNA gene copy numbers from DNA in Phase 1 were nearly doubled in Phase 2, copy numbers for mcrA gene in Phase 2 were 1 order of magnitude higher than in Phase 1. Both eubacteria and methanogenic archaea abundance recovery in the $\mathrm{AD}$ was also remarkable in the $16 \mathrm{~S} r R N A$ and $m c r A$ transcript abundance, with a 4.5-fold raise in Phase 2. These results perfectly correlate with the higher AD methane production in Phase 2 (section 3.3) with respect to Phase 1. Lower $16 \mathrm{~S}$ rRNA gene copy numbers in Phase 1 may suggest that ammonia and VFA toxicity does not only affect methanogenic archaea but also the hydrolysis and acidification processes performed by eubacteria, as stated in a previous work (El-Mashad et al. 2004; Veeken et al., 2000).

The MEC population showed similar gene copy numbers in terms of DNA for both genes at the start and at the end of the assay, pointing out a high stability of the anode biofilm population despite the changes introduced through the influent and the inhibition of the AD. The increase in $16 S$ rRNA abundance was concomitant to a decrease in $m c r$ A transcripts (active methanogens). This fact would suggest that eubacteria populations, including the exoelectrogenic group among them, are largely able to outcompete methanogenic archaea for organic substrates utilisation in these systems. Factors such as a high anode overpotential may favour this result, even when operating the MEC with a high OLR (Sleutels et al., 2016).

Therefore, combining simultaneous DNA and total RNA extraction has proven to be a useful technique to understand biomass dynamics in the bioreactors, gaining insight in its truly active population.

\subsubsection{DNA and cDNA based high throughput sequencing of eubacteria and archaea}

The reads and coverage obtained for bacteria and archaea communities for each sample are shown in Table 3. Figure $4 \mathrm{a}$ shows that the dominant eubacterial phylum in the $\mathrm{AD}$, at the end of Phase 1, was Firmicutes (85\%). At the end of Phase 2 its relative abundance decreased to 64\%, while Bacteroidetes increased from $8 \%$ to $22 \%$. However, when looking at RNA-level active populations, Firmicutes reduced its relative abundance from $81 \%$ to $35 \%$, while Proteobacteria increased its activity showing a $48 \%$ relative abundance in Phase 2 (2\% in Phase 1). At family level, Clostridiaceae (42\%) and Peptostreptococcaceae (19\%) were the predominant groups at the end of Phase 1 and Phase 2 (22\% and 13\% respectively), considering that during 
the inhibited state -Phase $1-40 \%$ of the reads for cDNA were unclassified sequences at $80 \%$ cut-off values, in agreement with the RDP Bayesian Classifier (Wang et al. 2007) (Figure 4b).

In the MEC anode biofilm, Firmicutes (39\%) and Bacteroidetes (25\%) were the dominant eubacterial phyla, followed by Proteobacteria (9\%), presenting almost no changes between the samples at the start and at the end of the assay $(35 \%, 30 \%$ and $11 \%$, respectively, at the end of Phase 2) (Figure 4a). These three phyla have been also identified in previous studies in BES (Bonmatí et al. 2013; Sotres et al. 2015b; Cerrillo et al. 2016b). When looking at active members Proteobacteria, Firmicutes and Bacteroidetes accounted for around $70 \%$ of cDNA relative abundance in both samples. In addition, a new phylum appeared among the dominant ones, Planctomycetes (17\% in both samples), despite its low relative abundance in the $16 S$ rDNA amplicon reads (2\%). Planctomycetes phylum is poorly known, and has been previously described in MFCs focusing on Anammox processes ( $\mathrm{Li}$ et al. 2015) or with wastewater or sludge inoculums (Kim et al. 2006; Zhang et al. 2012). At family level (Figure 4b), Clostridiaceae, Flavobacteriaceae and sample (17\%, 19\% and 10\%, respectively). However, Desulfuromonadaceae, which has been reported as an electroactive family in BES reactors (Logan 2009) and has been enriched under MEC mode operation (Cerrillo et al. 2016a), was revealed as the most active family of all (18\% and 19\% relative abundances at cDNA level in the initial and final samples, respectively), followed by Planctomycetaceae (17\% in both samples).

Regarding archaeal community (Figure 5), an increase in Methanobacteriaceae relative abundance was observed from inhibited (73\%) to stable phase (86\%) in the $\mathrm{AD}$, concomitant with a decrease in Methanomicrobiaceae (from 16 to 5\%, respectively), being all the genus of both families exclusively hydrogenotrophic methanogens, such as Methanoculleus, Methanobrevibacter or Methanothermobacter. Changes of $m c r A$ transcripts abundance in the AD have been more perceptible, accordingly to a previous study which suggested that methanogens in anaerobic sludge had a strong $m c r$ A transcriptional response to ammonia stress without a change in the community structure (Zhang et al. 2014). For example, Methanotrichaceae (Methanosaeta), a minor acetotrophic family detected in DNA analysis, revealed as an active microorganism at the end of Phase 1, although suffering a sharp decrease during stable state (from 31 to $1 \%$ ). This family was present in previous phases of the operation of the $\mathrm{AD}$, as described elsewhere 
(Cerrillo et al. 2016b), so its detection in Phase 1 may reflect the evolution from this state. In turn,

Methanobacteriaceae and Methanomassiliicoccaceae families, hydrogenotrophic and methylotrophic methanogens, respectively, increased their activity (cDNA) during stable operation (accounting from 15 to $36 \%$ and from 11 to 24\%, respectively), while Methanomicrobiaceae remained stable (42 and 38\% in Phase 1 and 2, respectively). Independently from the changes produced in the AD operation and methane production, the composition and activity of the biomass remained mainly dominated by hydrogenotrophic genus, probably due to high ammonia concentrations in the reactor, since acetotrophic methanogens are usually more sensitive to the inhibitory effect of FAN $\left(\mathrm{IC}_{50}=250 \mathrm{mg} \mathrm{L}^{-1}\right)$. FAN levels in the reactor were high enough to selectively inhibit their growth; and the low HRT of the anaerobic reactor also favoured the growth of hydrogenotrophic methanogens. High concentrations of ammonia in the reactor may be favouring the occurrence of potential syntrophic acetate oxidation processes (SAO) coupled to the hydrogenotrophic methanogenesis route, which consists in the oxidation of methyl and carboxyl groups of acetate to $\mathrm{CO}_{2}-$ producing $\mathrm{H}_{2}$ - catalysed by syntrophic acetate-oxidising bacteria (SAOB) (Hattori 2008). Possible SAOB, such as Syntrophaceticus or Tepidanaerobacter, were detected in the AD samples, although showing low relative abundances $(0.75 \%$ and $0.48 \%$ for Phase 1 and 2 , respectively). Aside from them being more abundant in Phase 1- inhibited state- they were also more active in this phase $(0.29 \%)$ with respect to Phase $2(0.05 \%)$, where the recirculation loop with the MEC was connected.

In the case of the MEC anode biofilm, the predominant and most metabolically active phylotypes belonged to the archaea family of Methanotrichaceae, either in the initial or the final sample (90\% and $87 \%$ for DNA and $97 \%$ and $89 \%$ for cDNA, respectively), showing a high stability in composition and activity irrespective of the changes in the influent. Contrary to these results, other studies have described the predominance of hydrogenotrophic methanogens on the BES anodes despite high concentrations of acetate in the substrate (Parameswaran et al. 2009; Lu et al. 2012a; Lu et al. 2012b; Shehab et al. 2013), and it is not clear if these archaea were growing using hydrogen gas or electrons transferred from exoelectrogenic bacteria, since direct electron transfer from the cathode to a methanogenic biofilm has been described recently (Cheng et al. 2009). A previous work also revealed the enrichment in Methanotrichaceae in a MEC working in continuous mode with digested pig slurry (Cerrillo et al. 2016b). On the other hand, Methanothrix (Methanosaeta) has been recently described as capable of accepting electrons via direct interspecies electron transfer (DIET) for 
the reduction of carbon dioxide to methane (Rotaru et al. 2014), so additional and further assessments are necessary to better understand the role of this species in the anode of a MEC.

\subsubsection{Biodiversity analysis}

Table 3 shows the results for the biodiversity analysis performed on the AD and MEC samples. Regarding eubacterial diversity, the inverted Simpson and Shannon indexes showed that, at the end of Phase 2, the AD

loop), where more different archaea can be active thanks to the improvement of the conditions in the reactor. Regarding the eubacterial diversity in the MEC anode biofilm, the initial sample showed a higher sample was more diverse than in Phase 1 . However, when looking at RNA-level, Phase 1 sample was revealed as the most diverse one. Archaeal biodiversity related to gene expression showed the opposite behaviour, with higher biodiversity in Phase 2, while at DNA level the richness of Phase 1 sample was slightly higher. These results correlate with a better performance of the AD in Phase 2 (with the recirculation biodiversity than the final one, either at DNA or cDNA level. A previous work also reported a loss in biodiversity in MEC biofilm when integrated with an AD (Cerrillo et al. 2016b). Biodiversity related to eubacterial 16S rRNA (cDNA level) in MEC was higher compared to both AD samples. This fact can be of great importance to maintain the stability of the system in case of AD inhibition. Biodiversity for archaea, per the inverted Simpson and Shannon Weaver indexes, was very similar at DNA level, while it was higher at the end of the assay when looking at RNA-level. In this case, contrary to the detected behaviour in eubacterial biodiversity, values for $m c r A$ transcripts and archaea $16 S$ rRNA diversity were lower in the MEC than in the AD samples, confirming that methanogenic processes are not as significant in MEC environments when compared to AD.

\subsubsection{Correspondence analysis}

Correspondence analysis results for the eubacteria community are shown in Figure 6a. MEC samples were distinctly similar than $\mathrm{AD}$ samples, as suspected by the similarity in relative abundance between the samples when carrying out the sequencing analysis. Furthermore, final MEC samples were significantly different from final $\mathrm{AD}$ samples, suggesting that regardless of the recirculation loop, both populations are able to evolve independently. The highest differentiation corresponded to AD samples regarding gene expression (cDNA), since the sequencing results showed a higher diversification in population, with an increase of the "Others" group, formed by families with less than $1 \%$ in relative abundance. 
When it comes to archaeal community, Figure $6 \mathrm{~b}$ shows that MEC samples were clustered together, while AD samples for DNA were clearly differentiated from cDNA samples. These results suggest that the MEC archaeal community was well established and maintained certain stability in composition irrespective of slight variations in activity when the characteristics of the influent were changed. However, AD samples showed higher differences, either comparing the inhibited with the stable phase, or between composition and microbial activity of the community itself. Summing up, microbial activity of the AD samples seemed to be less correlated to the composition of community than in the case of MEC samples.

\section{Conclusions}

As a conclusion, setting up the recirculation loop between the AD and the MEC allowed the former to tolerate a high organic and nitrogen loading rate which otherwise would result in the inhibition of the reactor, increasing methane production from 0.03 to $0.55 \mathrm{~m}^{3} \mathrm{~m}^{-3} \mathrm{~d}^{-1}$. Furthermore, the MEC process was able to improve the quality of the digestate during $\mathrm{AD}$ inhibition, achieving a maximum $\mathrm{COD}$ and ammonium removal efficiency of $29 \%$ and $34 \%$, respectively, and overall AD-MEC COD removal efficiencies close to $60 \%$. The microbial analysis of the AD biomass and the biofilm of the MEC anode showed that composition of the population differed in trully active microorganisms according to cDNA amplicon sequencing. Regarding AD biomass, it was dominated by hydrogenotrophic methanogens (Methanobacteriaceae), due to high ammonia concentrations in the reactor. The MEC biofilm was stable both in diversity and activity. Desulfuromonadaceae was revealed as the most active family in the MEC (18\%-19\% of cDNA relative abundance in Phase 1 and 2) even if not being the predominant family in DNA analysis. Furthermore, the population of both reactors remained well differentiated despite the existence of the recirculation loop, increasing the biodiversity of the system and suggesting that this configuration is more tolerant to stress than an $\mathrm{AD}$ operating alone. Finally, the results obtained demonstrated that $\mathrm{AD}$ microbial populations were altered in response to stress, while the MEC consortium maintained its stability.

The comparison between existing and active microorganisms through DNA and RNA extraction has revealed important differences in the data obtained proving that the analysis of $16 \mathrm{~S}$ rRNA at RNA level and $m c r A$ transcript abundance is essential to evaluate the relationships and functions of the different families of microorganisms. 


\section{Acknowledgements}

The authors would like to acknowledge the valuable contribution to this work of Miriam Guivernau (GIRO

Joint Research Unit IRTA-UPC), for the implementation of the protocols of RT-qPCR and simultaneous

DNA and RNA extraction with cDNA synthesis. This research was funded by the Spanish Ministry of

Economy and Competitiveness (INIA project RTA2012-00096-00-00). The first author was supported by a

$\mathrm{PhD}$ grant from the Secretariat for Universities and Research of the Ministry of Economy and Knowledge of

the Catalan Government (pre-doctoral grant 2013FI_B 00014).

\section{References}

Angelidaki, I., Ahring, B.K., 1993. Thermophilic anaerobic digestion of livestock waste: the effect of ammonia. Applied Microbiology and Biotechnology 38, 560-564.

Bonmatí, A., Sotres, A., Mu, Y., Rozendal, R.A., Rabaey, K., 2013. Oxalate degradation in a bioelectrochemical system: Reactor performance and microbial community characterization. Bioresource Technology 143, 147-153.

Cerrillo, M., Oliveras, J., Viñas, M., Bonmatí, A., 2016a. Comparative assessment of raw and digested pig slurry treatment in bioelectrochemical systems. Bioelectrochemistry 110, 69-78.

Cerrillo, M., Viñas, M., Bonmatí, A., 2016b. Overcoming organic and nitrogen overload in thermophilic anaerobic digestion of pig slurry by coupling a microbial electrolysis cell. Bioresource Technology 216, 362-372.

Chen, Y., Cheng, J.J., Creamer, K.S., 2008. Inhibition of anaerobic digestion process: A review. Bioresource Technology 99, 4044-4064.

Cheng, S., Xing, D., Call, D.F., Logan, B.E., 2009. Direct biological conversion of electrical current into methane by electromethanogenesis. Environmental Science \& Technology 43, 3953-3958.

Desloover, J., De Vrieze, J., Van de Vijver, M., Mortelmans, J., Rozendal, R., Rabaey, K., 2014. Electrochemical nutrient recovery enables ammonia toxicity control and biogas desulfurization in anaerobic digestion. Environmental Science \& Technology 49, 948-955.

El-Mashad, H.M., Zeeman, G., van Loon, W.K.P., Bot, G.P.A., Lettinga, G., 2004. Effect of temperature and temperature fluctuation on thermophilic anaerobic digestion of cattle manure. Bioresource Technology 95, 191-201.

Hattori, S., 2008. Syntrophic acetate-oxidizing microbes in methanogenic environments. Microbes and Environment 23, 118-127.

Ho, L., Ho, G., 2012. Mitigating ammonia inhibition of thermophilic anaerobic treatment of digested piggery wastewater: Use of pH reduction, zeolite, biomass and humic acid. Water Research 46, 4339-4350.

Kim, G.T., Webster, G., Wimpenny, J.W.T., Kim, B.H., Kim, H.J., Weightman, A.J., 2006. Bacterial community structure, compartmentalization and activity in a microbial fuel cell. Journal of Applied Microbiology 101, 698-710.

Lauterböck, B., Ortner, M., Haider, R., Fuchs, W., 2012. Counteracting ammonia inhibition in anaerobic digestion by removal with a hollow fiber membrane contactor. Water Research 46, 4861-4869. 
Lee, J., Hwang, B., Koo, T., Shin, S.G., Kim, W., Hwang, S., 2014. Temporal variation in methanogen communities of four different full-scale anaerobic digesters treating food waste-recycling wastewater. Bioresource Technology 168, 59-63.

Li, C., Ren, H., Xu, M., Cao, J., 2015. Study on anaerobic ammonium oxidation process coupled with denitrification microbial fuel cells (MFCs) and its microbial community analysis. Bioresource Technology 175, 545-552.

Logan, B.E., 2009. Exoelectrogenic bacteria that power microbial fuel cells. Nature Reviews Microbiology 7, 375-381.

Lu, L., Xing, D., Ren, N., 2012a. Bioreactor performance and quantitative analysis of methanogenic and bacterial community dynamics in microbial electrolysis cells during large temperature fluctuations. Environmental Science \& Technology 46, 6874-6881.

Lu, L., Xing, D., Ren, N., 2012b. Pyrosequencing reveals highly diverse microbial communities in microbial electrolysis cells involved in enhanced $\mathrm{H} 2$ production from waste activated sludge. Water Research 46, 2425-2434.

Munk, B., Bauer, C., Gronauer, A., Lebuhn, M., 2012. A metabolic quotient for methanogenic Archaea. Water Science and Technology 66, 2311-2317.

Neidhardt, F.C., C.I.R., Ingraham, J.L., Lin, E.C.C, Low, K.B., Magasanik, B., Reznikoff, W.S., Riley, M., Schaechter, M., Umbarger, H.E., eds, 1996. Escherichia coli and Salmonella: cellular and molecular biology. ASM Press, Washington, D.C.

Palatsi, J., Laureni, M., Andres, M.V., Flotats, X., Nielsen, H.B., Angelidaki, I., 2009. Strategies for recovering inhibition caused by long chain fatty acids on anaerobic thermophilic biogas reactors. Bioresource Technology 100, 4588-4596.

Parameswaran, P., Torres, C.I., Lee, H.-S., Krajmalnik-Brown, R., Rittmann, B.E., 2009. Syntrophic interactions among anode respiring bacteria (ARB) and Non-ARB in a biofilm anode: electron balances. Biotechnology and Bioengineering 103, 513-523.

Ripley, L.E., Boyle, W.C., Converse, J.C., 1986. Improved alkalimetric monitoring for anaerobic digestion of high-strength wastes. Journal (Water Pollution Control Federation) 58, 406-411.

Rotaru, A.-E., Shrestha, P.M., Liu, F., Shrestha, M., Shrestha, D., Embree, M., Zengler, K., Wardman, C., Nevin, K.P., Lovley, D.R., 2014. A new model for electron flow during anaerobic digestion: direct interspecies electron transfer to Methanosaeta for the reduction of carbon dioxide to methane. Energy \& Environmental Science 7, 408-415.

Schloss, P.D., Westcott, S.L., Ryabin, T., Hall, J.R., Hartmann, M., Hollister, E.B., Lesniewski, R.A., Oakley, B.B., Parks, D.H., Robinson, C.J., Sahl, J.W., Stres, B., Thallinger, G.G., Van Horn, D.J., Weber, C.F., 2009. Introducing mothur: open-source, platform-independent, community-supported software for describing and comparing microbial communities. Applied and Environmental Microbiology 75, 7537-7541.

Shehab, N., Li, D., Amy, G.L., Logan, B.E., Saikaly, P.E., 2013. Characterization of bacterial and archaeal communities in air-cathode microbial fuel cells, open circuit and sealed-off reactors. Applied Microbiology and Biotechnology 97, 9885-9895.

Sleutels, T.H.J.A., Molenaar, S.D., Heijne, A.T., Buisman, C.J.N., 2016. Low Substrate Loading Limits Methanogenesis and Leads to High Coulombic Efficiency in Bioelectrochemical Systems. Microorganisms 4, 7.

Sotres, A., Cerrillo, M., Viñas, M., Bonmatí, A., 2015a. Nitrogen recovery from pig slurry in a twochambered bioelectrochemical system. Bioresource Technology 194, 373-382.

Sotres, A., Díaz-Marcos, J., Guivernau, M., Illa, J., Magrí, A., Prenafeta-Boldú, F.X., Bonmatí, A., Viñas, M., 2015b. Microbial community dynamics in two-chambered microbial fuel cells: effect of different ion exchange membranes. Journal of Chemical Technology \& Biotechnology 90, 1497-1506.

Veeken, A., Kalyuzhnyi, S., Scharff, H., Hamelers, B., 2000. Effect of pH and VFA on hydrolysis of organic solid waste. Journal of Environmental Engineering 10, 1076-1081.

Wang, Q., Garrity, G.M., Tiedje, J.M., Cole, J.R., 2007. Naïve bayesian classifier for rapid assignment of rRNA sequences into the new bacterial taxonomy. Applied and Environmental Microbiology 73, 5261-5267.

Wang, Y., Zhang, Y., Wang, J., Meng, L., 2009. Effects of volatile fatty acid concentrations on methane yield and methanogenic bacteria. Biomass and Bioenergy 33, 848-853. 
457 Yenigün, O., Demirel, B., 2013. Ammonia inhibition in anaerobic digestion: A review. Process Biochemistry 48, 901-911.

459 Zhang, C., Yuan, Q., Lu, Y., 2014. Inhibitory effects of ammonia on methanogen mcrA transcripts in 460 461 462 anaerobic digester sludge. FEMS Microbiology Ecology 87, 368-377.

Zhang, G., Zhao, Q., Jiao, Y., Wang, K., Lee, D.-J., Ren, N., 2012. Efficient electricity generation from sewage sludge using biocathode microbial fuel cell. Water Research 46, 43-52. 
468 Table 1. Characterisation of the pig slurry used as feeding in the anaerobic digester (AD) ( $\mathrm{n}=$ number of samples). 469

\begin{tabular}{|c|c|}
\hline Parameter & Value \\
\hline $\mathrm{pH}(-)$ & $7.0 \pm 0.1$ \\
\hline $\mathrm{COD}\left(\mathrm{g}_{\mathrm{O} 2} \mathrm{~kg}^{-1}\right)$ & $62.63 \pm 2.96$ \\
\hline $\mathrm{TKN}\left(\mathrm{g} \mathrm{L}^{-1}\right)$ & $3.65 \pm 0.11$ \\
\hline $\mathrm{NH}_{4}^{+}-\mathrm{N}\left(\mathrm{g} \mathrm{L}^{-1}\right)$ & $2.66 \pm 0.27$ \\
\hline $\mathrm{TS}\left(\mathrm{g} \mathrm{kg}^{-1}\right)$ & $35.80 \pm 0.72$ \\
\hline $\mathrm{VS}\left(\mathrm{g} \mathrm{kg}^{-1}\right)$ & $23.50 \pm 1.21$ \\
\hline $\mathrm{n}$ & 10 \\
\hline
\end{tabular}

470

471

472 
474 Table 2. Operational conditions of the AD reactor.

\begin{tabular}{ccccc}
\hline Phase & Period (d) & $\begin{array}{c}\text { OLR } \\
\left(\mathbf{k g}_{\operatorname{coD}} \mathbf{~}^{-\mathbf{3}} \mathbf{d a y}^{-\mathbf{1}}\right)\end{array}$ & $\begin{array}{c}\mathbf{N L R} \\
\left(\mathbf{k g}_{\mathbf{N}} \mathbf{~ m}^{-\mathbf{3}} \mathbf{d a y}^{-\mathbf{1}}\right)\end{array}$ & $\begin{array}{c}\text { Recirculation } \\
(\% \text { of feed flow rate) }\end{array}$ \\
\hline 1 & $1-15$ & $6.10 \pm 1.88$ & $0.35 \pm 0.04$ & 0 \\
2 & $16-118$ & & 50 \\
\hline
\end{tabular}

475

476

477 
Table 3. Diversity index for Eubacterial and Archaeal community of the effluent of the AD by the end of Phase 1 and Phase 2 and the initial and final MEC anode biofilm (MECi and MECf, respectively) (mean \pm standard deviation). Data normalised to the sample with the lowest number of reads (36854 and 62211 for eubacteria and archaea, respectively).

\begin{tabular}{lccccc}
\hline & Reads & Coverage & OTUs & $\begin{array}{c}\text { Inverted } \\
\text { Simpson }\end{array}$ & Shannon \\
\hline Eubacteria & & & & & \\
\hline DA-Ph1-DNA & 50674 & $0.94 \pm 0.00$ & $373 \pm 12$ & $12.0 \pm 0.4$ & $3.64 \pm 0.04$ \\
DA-Ph2 DNA & 50751 & $0.91 \pm 0.00$ & $550 \pm 15$ & $31.1 \pm 1.1$ & $4.52 \pm 0.03$ \\
DA-Ph1-cDNA & 50897 & $0.94 \pm 0.00$ & $391 \pm 12$ & $17.2 \pm 0.5$ & $3.88 \pm 0.03$ \\
DA-Ph2-cDNA & 86842 & $0.94 \pm 0.00$ & $352 \pm 12$ & $7.3 \pm 0.3$ & $3.34 \pm 0.04$ \\
MECi-DNA & 46644 & $0.91 \pm 0.00$ & $617 \pm 15$ & $33.0 \pm 1.3$ & $4.76 \pm 0.03$ \\
MECf-DNA & 36854 & $0.91 \pm 0.00$ & $549 \pm 15$ & $19.4 \pm 0.8$ & $4.34 \pm 0.04$ \\
MECi-cDNA & 46641 & $0.92 \pm 0.00$ & $533 \pm 14$ & $27.5 \pm 1.0$ & $4.51 \pm 0.03$ \\
MECf-cDNA & 37766 & $0.92 \pm 0.00$ & $535 \pm 15$ & $17.8 \pm 0.7$ & $4.33 \pm 0.04$ \\
\hline Archaea & & & & & \\
\hline DA-Ph1-DNA & 102718 & $0.98 \pm 0.01$ & $18 \pm 3$ & $1.8 \pm 0.1$ & $1.11 \pm 0.08$ \\
DA-Ph2 DNA & 87626 & $0.97 \pm 0.01$ & $23 \pm 3$ & $1.5 \pm 0.1$ & $0.90 \pm 0.09$ \\
DA-Ph1-cDNA & 62211 & $0.98 \pm 0.01$ & $26 \pm 3$ & $4.8 \pm 0.3$ & $2.01 \pm 0.06$ \\
DA-Ph2-cDNA & 64716 & $0.96 \pm 0.01$ & $33 \pm 3$ & $7.9 \pm 0.4$ & $2.41 \pm 0.06$ \\
MECi-DNA & 112133 & $0.97 \pm 0.01$ & $19 \pm 3$ & $1.3 \pm 0.1$ & $0.68 \pm 0.08$ \\
MECf-DNA & 106114 & $0.98 \pm 0.01$ & $15 \pm 3$ & $1.4 \pm 0.1$ & $0.70 \pm 0.07$ \\
MECi-cDNA & 132548 & $0.98 \pm 0.01$ & $10 \pm 2$ & $1.1 \pm 0.0$ & $0.34 \pm 0.06$ \\
MECf-cDNA & 136706 & $0.98 \pm 0.01$ & $17 \pm 3$ & $1.3 \pm 0.0$ & $0.58 \pm 0.07$ \\
\hline
\end{tabular}




\section{Figure captions}

Figure 1 Performance of the AD regarding (a) COD removal efficiency; (b) methane production; (c) VFA concentration; and (d) IA:TA ratio.

Figure 2 Performance of the MEC regarding current density and COD and ammonium removal efficiency (phase 2).

Figure 3 Gene copy numbers and transcripts for $16 S$ rRNA and $m c r A$ genes and DNA-cDNA ratio between them (DNA as gene and cDNA as gene transcript), of the effluent of the AD by the end of Phase 1 and Phase 2 and the initial and final MEC anode biofilm (MECi and MECf, respectively).

Figure 4 Taxonomic assignment of sequencing reads from the Eubacterial community of the effluent of the AD by the end of Phase $1(\mathrm{Ph} 1)$ and Phase $2(\mathrm{Ph} 2)$ and the initial and final MEC anode biofilm (MECi and MECf, respectively) for DNA and cDNA, at a) phylum b) family levels. Relative abundance was defined as the number of reads (sequences) affiliated with any given taxon divided by the total number of reads per sample. Phylogenetic groups with a relative abundance lower than $1 \%$ were categorised as "others".

Figure 5 Taxonomic assignment of sequencing reads from Archaeal community of the effluent of the AD by the end of Phase $1(\mathrm{Ph} 1)$ and Phase $2(\mathrm{Ph} 2)$ and the initial and final MEC anode biofilm (MECi and MECf, respectively) for DNA and cDNA at family level. Relative abundance was defined as the number of reads (sequences) affiliated with any given taxon divided by the total number of reads per sample. Phylogenetic groups with a relative abundance lower than $1 \%$ were categorised as "others".

Figure 6 Correspondence Analysis of the effluent of the AD by the end of Phase $1(\mathrm{Ph} 1)$ and Phase $2(\mathrm{Ph} 2)$ and the initial and final MEC anode biofilm (MECi and MECf, respectively) for DNA and cDNA samples regarding (a) Eubacteria and (b) Archaea communities. 
Figure 1

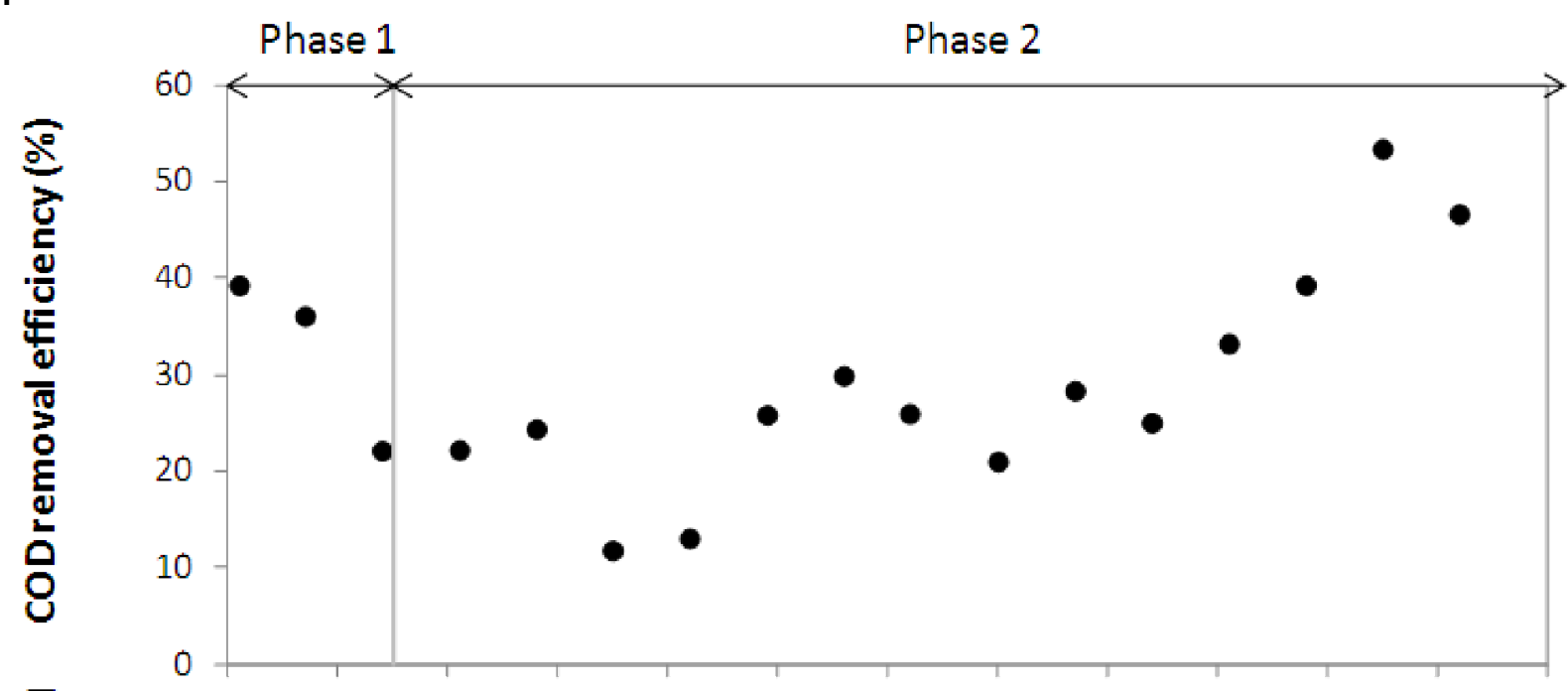

b)

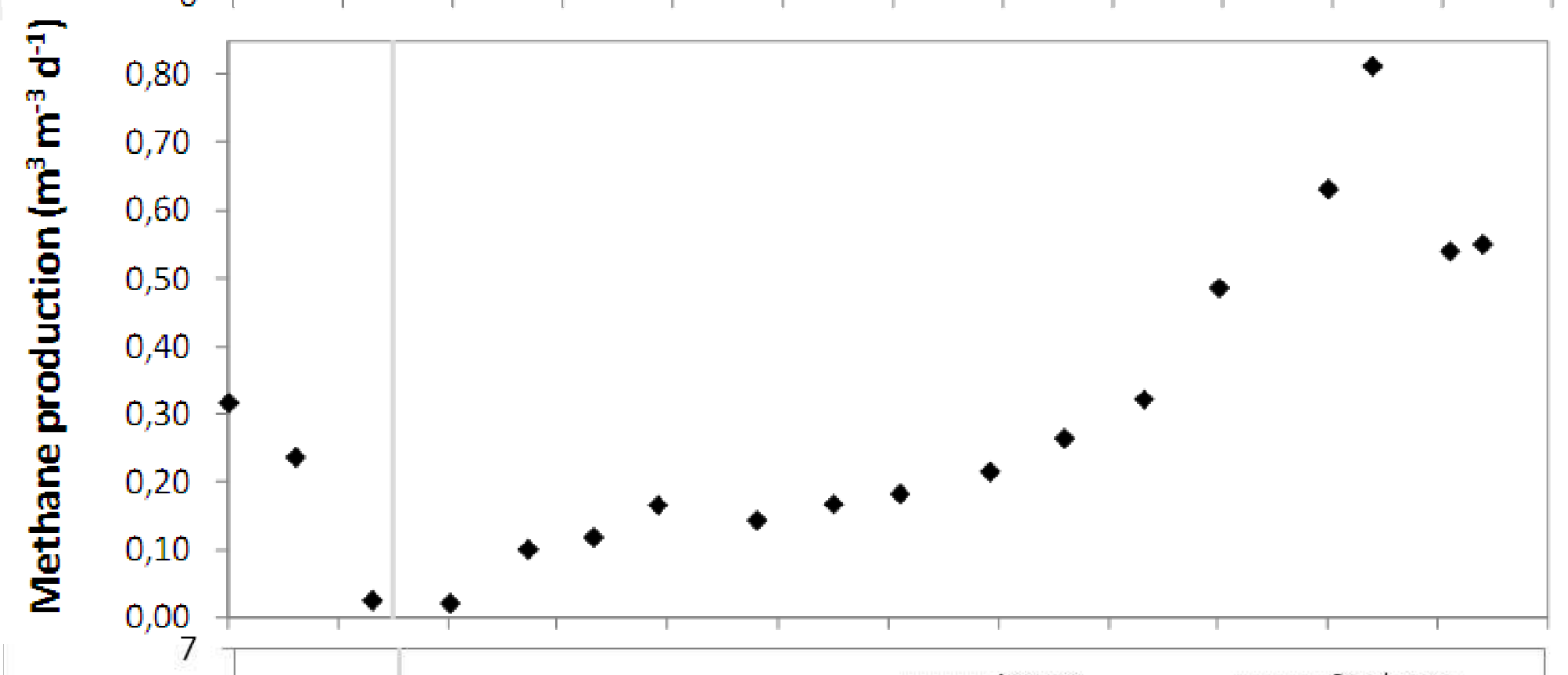

c)

d)
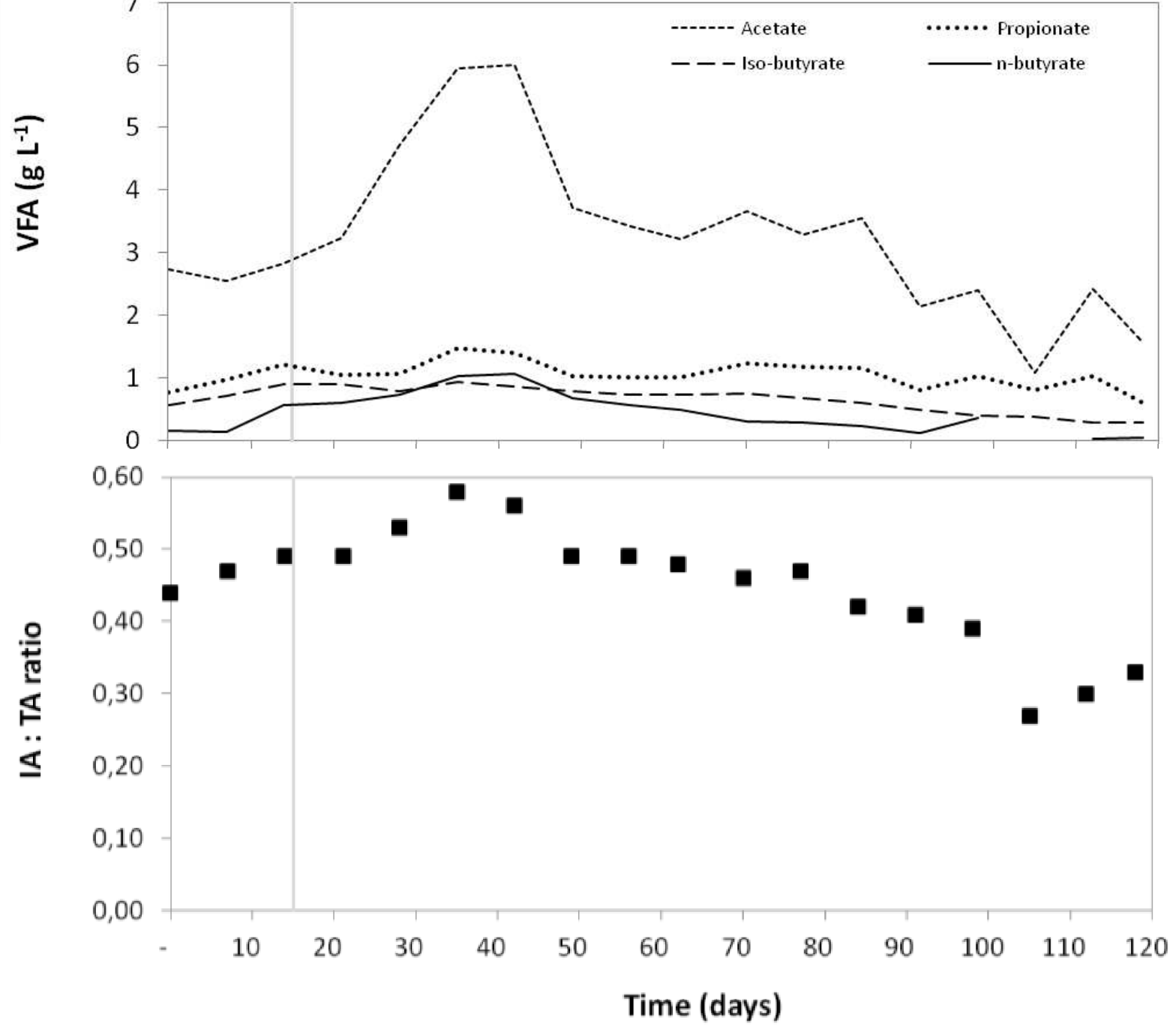


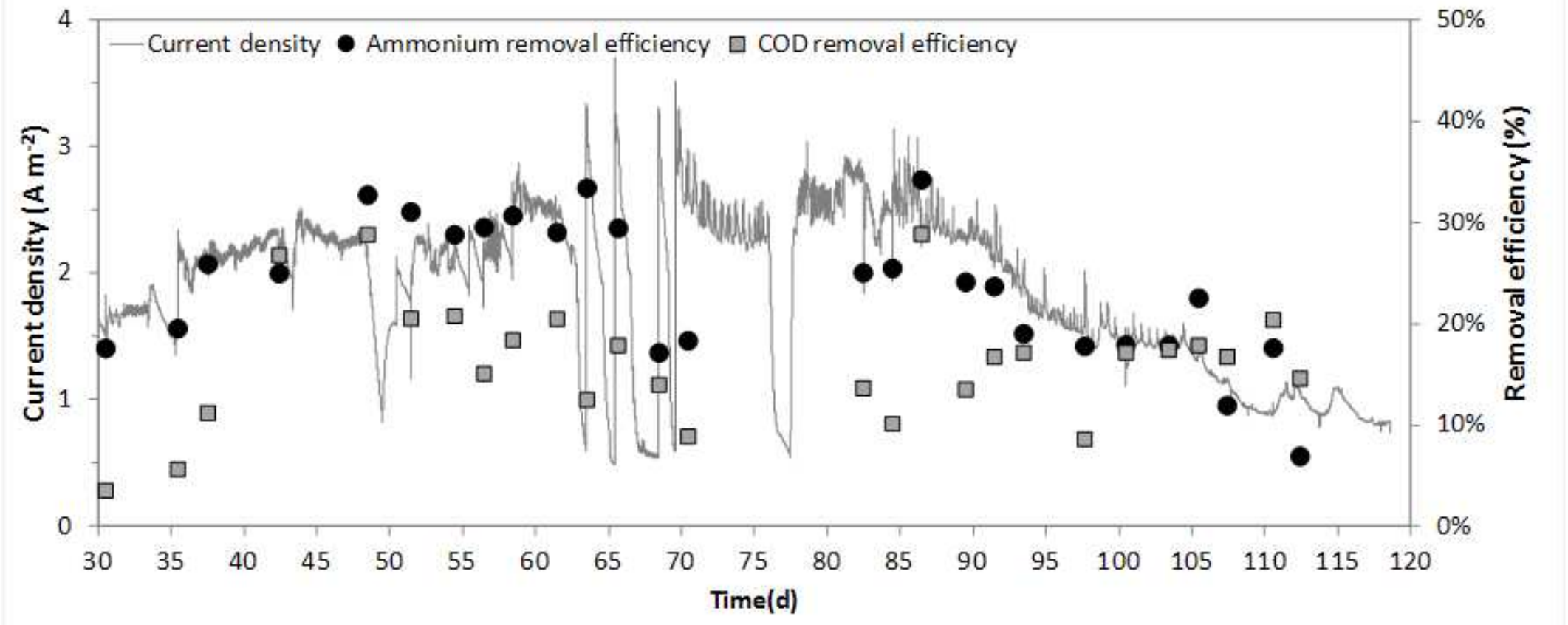


Figure 40
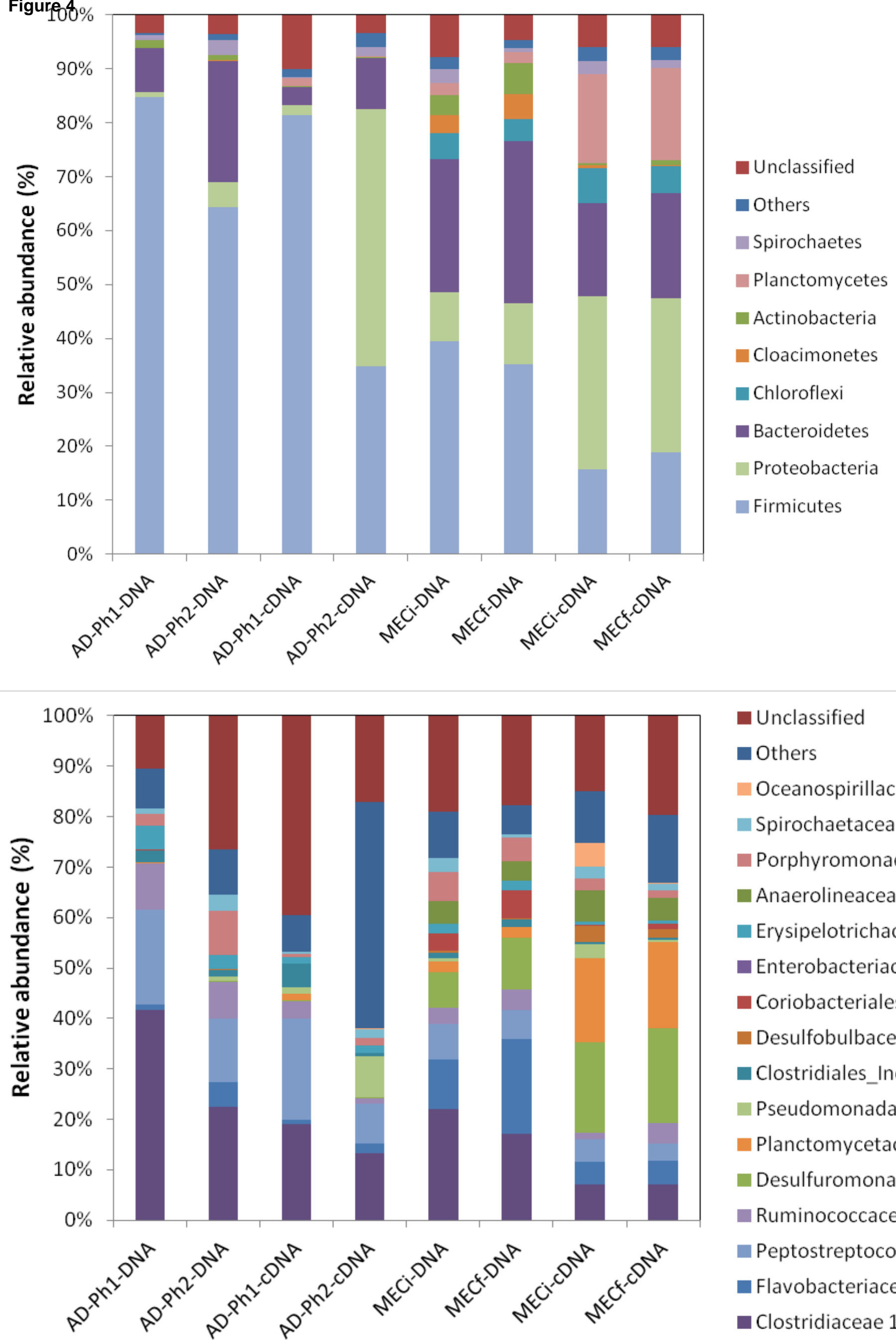

- Unclassified

口 Others

Oceanospirillaceae

- Spirochaetaceae

- Porphyromonadaceae

Anaerolineaceae

Erysipelotrichaceae

- Enterobacteriaceae

Coriobacteriales

Desulfobulbaceae

- Clostridiales_Incertae Sedis

- Pseudomonadaceae

- Planctomycetaceae

- Desulfuromonadaceae

- Ruminococcaceae

Peptostreptococcaceae

- Flavobacteriaceae

- Clostridiaceae 1 
Figure 5

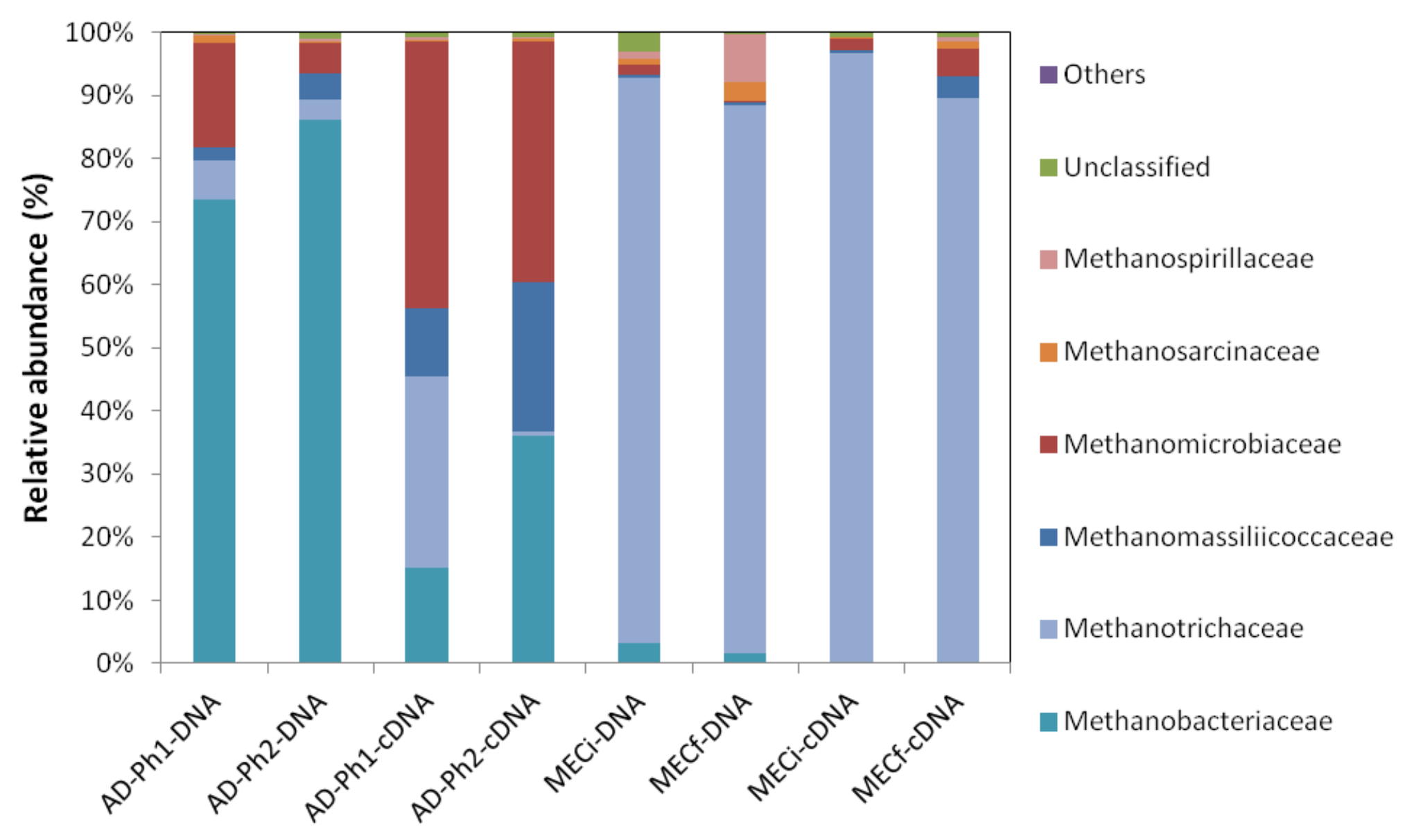


Figure 6

a)

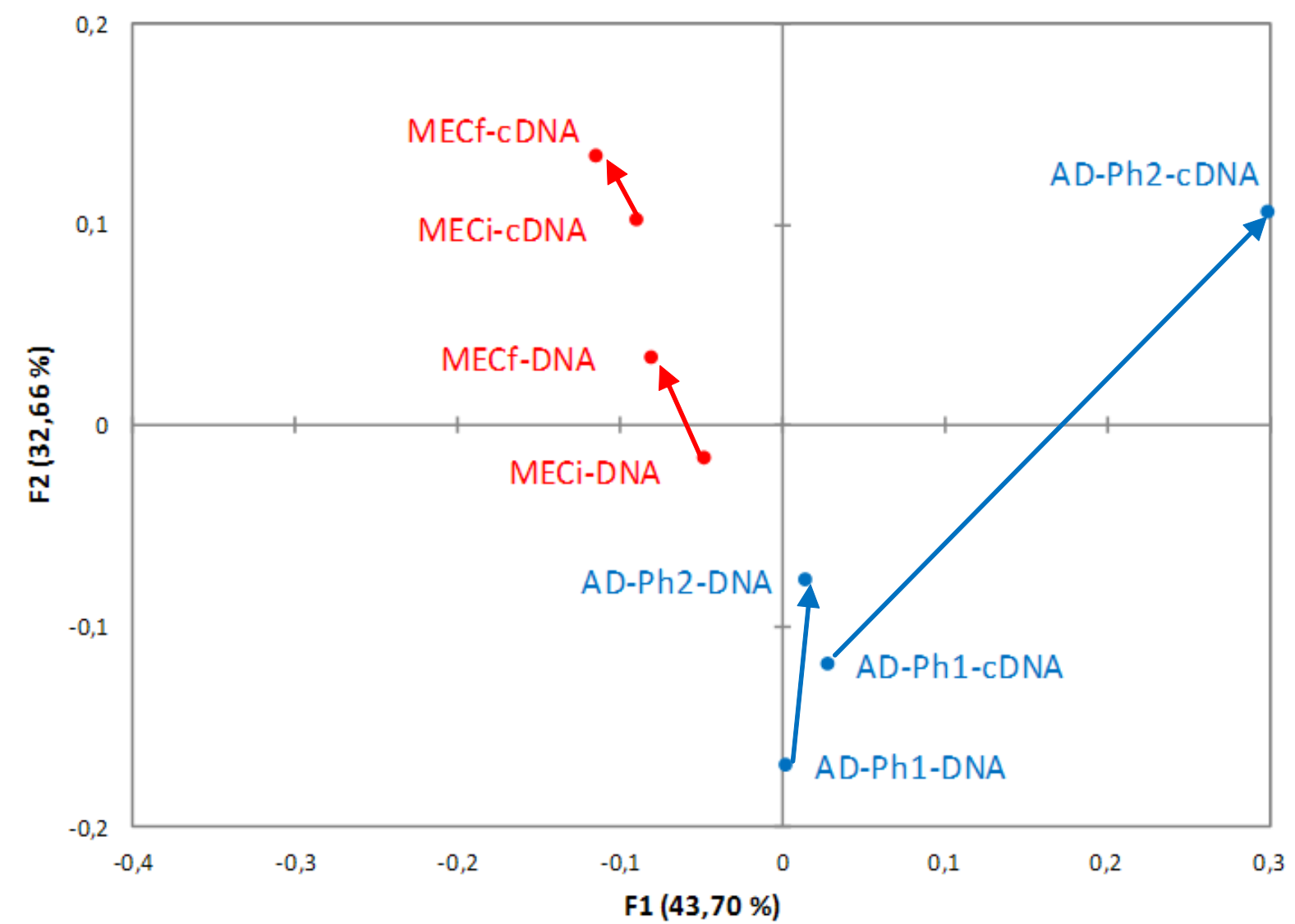

Correspondence Analysis Archaea

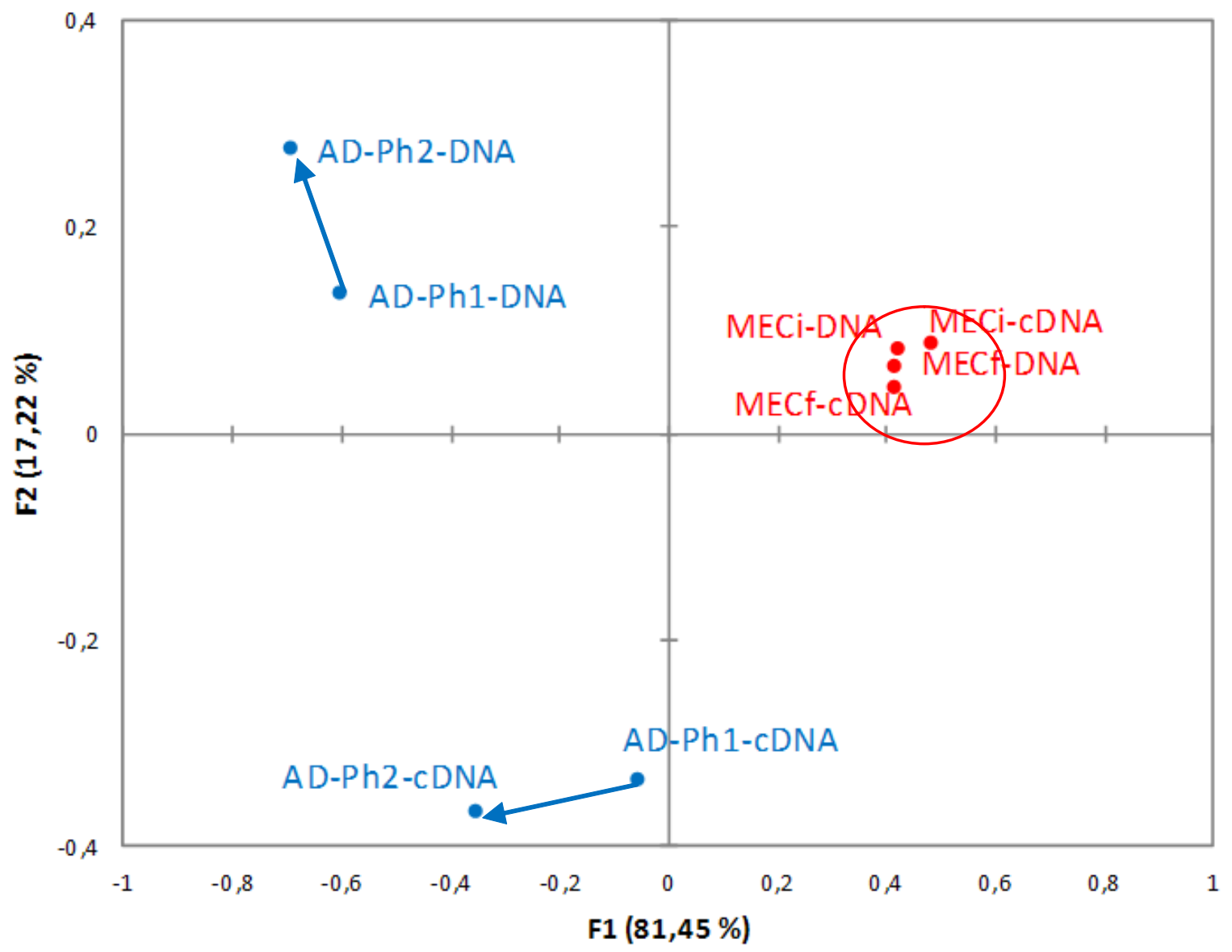

